order to enable the possibility of comparing results on an international basis.

\section{PREVALENCE AND RISK FACTORS FOR HAND ECZEMA AMONG NORWEGIAN SPECIALIST NURSES: A CROSS- SECTIONAL STUDY}

${ }^{1} \mathrm{LC}$ Resch* ${ }^{1}$ I Sandven, ${ }^{2} \mathrm{P}$ Brenno, ${ }^{2} \mathrm{~T}$ Bakkerud, ${ }^{3} \mathrm{TE}$ Danielsen, ${ }^{4} \mathrm{JH}$ Alfonso. ${ }^{1} \mathrm{Dep}$. of Occupational and Environmental Medicine. Oslo University Hospital, Oslo, Norway; ${ }^{2}$ Occupational Health Service. Oslo University Hospital, Oslo, Norway; ${ }^{3}$ Norwegian Labour Inspectorate, Trondheim, Norway; ${ }^{4}$ Depatment of Occupational Medicine and Epidemiology, National Institute of Occupational Health, Oslo. Norway

\subsection{6/oemed-2018-ICOHabstracts.970}

Background Hand eczema (HE), the most frequent workrelated skin disease, is common among health workers, but knowledge about its occurrence in Norwegian specialist nurses is scarce.

We aimed to investigate the prevalence of hand eczema and identify occupational and non-occupational risk factors among specialist nurses working at the Oslo University Hospital.

Methods A cross-sectional survey of 115 specialist nurses (surgical and anestesics) was performed by using an adapted version of the Nordic Occupational Skin Questionnaire (NOSQ 2002-Norwegian), which includes standardised questions for $\mathrm{HE}$, occupational and non-occupational exposures. Analyses comprised descriptive statistics and logistic regression (STATA 14).

Results The participation frequency was 99.1\%. Nearly threequarters of the participants reported skin symptoms during the last 12 months. The lifetime prevalence, one-year prevalence and point prevalence of $\mathrm{HE}$ was $27.19 \%, 17.54 \%$, and $11.40 \%$; the prevalence of work-related $\mathrm{HE}$ was $14.9 \%$. Although HE was more common in women, we did not find an association between sex and HE. Age, childhood eczema, and amount of years working as a specialist nurse were consistent predictors for work-related HE. Time spent using protective gloves did not predict work-related $\mathrm{HE}$, but selfreported skin symptoms when using protective gloves was a consistent predictor. The most common aggravating factors at work comprised hand cleaning and disinfection, water and winter season. Domestic exposures (food preparation, cleaning/ washing, care for children under 4 years, contact with animals) did not predict either HE or work-related HE.

Conclusion The one-year prevalence for $\mathrm{HE}$ was almost twice, and for work-related HE was nearly thrice than in the general population. The occurrence of work-related HE was associated with older age, childhood eczema, amount of years working as specialist nurse, and skin symptoms when wearing protective gloves. A potential healthy worker survivor effect may underestimate the prevalence figures and associations reported here. Prevention strategies focusing on skin care and protection should be developed for specialist nurses.

\section{\begin{tabular}{|l|l}
\hline 405 & UPPER EXTREMITIES STRAIN ASSESSMENT IN NURSING
\end{tabular} PERSONNEL}

${ }^{1}$ Davor Romih*, 'Dani Mirnik, 'Marjan Bilban, ${ }^{2}$ Tihomir Ratkajec. 'Institute of Occupational Safety, Department of Occupational Health, Ljubljana, Slovenia; ${ }^{2}$ Medicina dela Rogaška, Rogaška Slatina, Slovenia

10.1136/oemed-2018-ICOHabstracts.971
Introduction Besides work-related low back pain, disorders of neck-shoulder-arm area have also become increasingly common amongst nursing personnel. Analysis of working postures according to OWAS method demonstrated that more than $25 \%$ of the working time the abduction of the upper limb was between 30 and 90 degrees. At that point ergonomic measures should be considered. This study was conducted to determine whether different bed positions effect deltoid muscle activity during nursing tasks.

Methods Seven nurses in a geriatric nursing home participated in the study. Surface electromyography was used to assess local strain of the deltoid muscle during standardised morning care routine of immobile patients. Each participant conducted measurements with four different bed conditions: 1. recommended bed height according to the anthropometric characteristics with side rails up; 2. recommended height with side rails down; 3. recommended height lowered by 10 centimetres with side rails up; 4. lowered height with side rails down. Statistical analysis was performed on the basis of non-parametric Wilcoxon matched pairs test. The value $\mathrm{p}<0.05$ was considered to be statistically significant.

Result There were no statistically significant differences between all four cases. Deltoid muscle activity was neither influenced by the height of the bed $(p=0.078-1.00)$ nor by the positions of the side rails $(p=0,047-0.33)$.

Discussion Differences in bed height or the position of the side rails did not result in significant change of deltoid muscles activity. Therefore, further ergonomic evaluations need to be considered to determine the true origin of shoulder discomfort and why upper limb postures are above critical ergonomic values amongst nursing personnel.

\section{FEASIBILITY AND ACCEPTABILITY OF A WORK-BASED COLORECTAL CANCER SCREENING INITIATIVE IN FLORIDA FIREFIGHTERS}

\footnotetext{
${ }^{1,2}$ Natasha Schaefer Solle ${ }^{*},{ }^{1,2}$ Daniel Sussman, ${ }^{2,3}$ Alberto I Caban-Martinez, ${ }^{1,3}$ Colette Tse, ${ }^{1,3}$ Jennifer Tibangin, ${ }^{2,3}$ David I Lee, ${ }^{1,2}$ Erin N Kobetz. ${ }^{1}$ Department of Medicine, University of Miami, Miller School of Medicine, Miami, FL, USA; ${ }^{2}$ Sylvester Comprehensive Cancer Centre, University of Miami, Miami, FL, USA; ${ }^{3}$ Department of Public Health Sciences, University of Miami, Miller School of Medicine, Miami, FL, USA
}

10.1136/oemed-2018-ICOHabstracts.972

Introduction Colorectal cancer (CRC) has been identified as one of the top diagnosed cancers among firefighters in Florida, United States. Firefighters are routinely exposed to highly toxic materials, many of which have been linked to an increased risk for colorectal cancer. Despite the elevated risk, cancer screening behaviours of active firefighters are unknown. We assessed the feasibility, acceptability, and implementation of a worksite-based cancer screening program using faecal immunochemical testing (FIT) among unscreened and underscreened Florida firefighters.

Methods In collaboration with Florida fire departments, participants were recruited through their fire department. All participants completed an eligibility screener, informed consent and demographic questionnaire. Firefighters subsequently received a FIT kit in-person or via mail and returned specimens to the lab for testing. Screening results were reported to participants via telephone and those who screened positive were referred for colonoscopy.

Result Collectively, 1611 firefighters were screened for eligibility of whom $525(32.6 \%)$ were eligible. Ineligible firefighters 
were mainly excluded due to age $(n=635,58.5 \%)$ or were already current with CRC screening recommendations (154 [14.2\%] completed FIT in the previous year, and 132 [12.2\%] received a colonoscopy in the previous 10 years). FIT kits were sent to 496 of the eligible subjects; 310 (62.5\%) participants returned the kits, and $6(2.0 \%)$ received a positive FIT result. All FIT positive participants completed clinical followup with colonoscopy screening.

Discussion Firefighters in this study report that using FIT was easy or somewhat easy to perform and would prefer to use this test for screening in the future. Based on these preliminary findings, this workplace screening initiative was both feasible and acceptable in the sample of firefighters. A workplace cancer screening program has potential to increase screening rates in the firefighter population. Additional epidemiologic surveillance for annual screening follow-up is warranted.

\section{A STUDY ON THE WORKERS WITH LATENT TUBERCULOSIS INFECTION IN A TERTIARY HOSPITAL}

Gogillan Sevaratnam*. Kuala Lumpur Hospital, Federal Territory, Malaysia

\subsection{6/oemed-2018-ICOHabstracts.973}

Introduction The risk of contracting with Latent Tuberculosis Infection (LTBI) is higher among those who are dealing with patients directly. Control of LTBI is an important step towards tuberculosis elimination.

Methods LTBI was assessed by Tuberculin Skin Test by screening new workers and through contact tracing. A cross-sectional study of 362 workers infected with LTBI were detected from 2013-2016. The study was done to obtain the information on the gender, age, job category and workplace, results of chest X-ray, history of previous Bacillus Calmette-Guerin (BCG) vaccination and infection with tuberculosis. These data were collected from the Occupational Health Clinic of the hospital and a descriptive study was done.

Results 106 males (29.3\%) and 256 females (70.7\%) were evaluated. $60.2 \%$ of them were 30 years old and below. Majority were nurses $(31.8 \%)$ and $64.4 \%$ of the LTBI cases were detected from contact tracing. 261 workers $(72.1 \%)$ were from clinical departments. Majority of the workers $(76.5 \%)$ were known to be vaccinated with BCG. Only $1.6 \%$ of them had previous history of tuberculosis. As low as $12.2 \%$ of the workers had some chest x-ray changes on investigation and $17.7 \%$ were referred to pulmonologist due to various reasons. Out of 362 LTBI workers, six were found to have positive TB.

Discussion Although very few workers with LTBI became positive tuberculosis, the practices of tuberculosis infection control have to be strengthened in high risk places such as hospitals.

\section{WORK AND HEALTH: THE PERSPECTIVE OF THE ENDEMIC DISEASES COMBAT AGENTS THE MUNICIPALITY OF BELO HORIZONTE, BRAZIL}

${ }^{1} \mathrm{GC}$ Ribeiro, ${ }^{2} \mathrm{JM}$ da Silva, ${ }^{2} \mathrm{AM}$ Silveira. ${ }^{1}$ Municipal Health Department of Belo Horizonte, Belo Horizonte, Brazil; ${ }^{2}$ Universidade Federal de Minas Gerais, Belo Horizonte, Brazil

\subsection{6/oemed-2018-ICOHabstracts.974}

Introduction The purpose of this study was to understand the perception of the Endemic Diseases Combat Agents (EDCA) about their work context, mainly focusing the relationship between work and health, within the Municipal Health Department of Belo Horizonte.

Methods This is a qualitative study, under the theoretical contribution of the Work Clinics, with emphasis on Psychosociology and Clinic of Activity. The methodological procedures were bibliographic search, document analysis and focus group. The analysis of the data was based on the Bardin's Content Analysis.

Results The study showed that the professionals realise that the zoonosis service is not effectively integrated in health units. This not-belonging is one of the causes of the precarious working conditions, the feeling of invisibility and the symbolic and concrete marginalisation reported by the professionals. The Endemic Diseases Combat Agents recognise the risks to which they are exposed, highlighting the various forms of violence and lack of adequate equipment. Given the organisation of the work, they use strategies of resistance and build creative alternatives in order to defend the good work and for preservation of health at work.

Discussion An organisation reproduces a logic that prevails in society; values, expected behaviours, kinds of relationship, so it is important, the institution perceives its internal contradictions, questioning about its institutional mission and its practices. Thus, although laws and regulations define and encourage the integration of EDCA to primary care teams, this process still needs to be discussed collectively in the SMSA at all levels of management.

\section{WORKPLACE BULLYING AND ITS ASSOCIATION WITH DEPRESSION AND SELF-ESTEEM AMONG HEALTH CARE WORKERS IN SELECTED HOSPITALS IN SARAWAK}

PCM Chang, AT Su*, MM Mizanur. Universiti Malaysia Sarawak, Sarawak, Malaysia

\subsection{6/oemed-2018-ICOHabstracts.975}

Introduction Bullying at the workplace has been recognised as an increasing problem amongst healthcare staff, and has been associated with a low self-esteem and depression. Considering this view, this study was aimed to determine the proportion of bullying amongst healthcare workers in selected hospitals in Sarawak and its association between depression and selfesteem.

Methods A cross sectional study using self-administered questionnaires was done in three selected hospitals in Sarawak. The questionnaires were distributed to doctors, nurses and medical assistants during their teaching sessions. The questionnaires consisted of socio-demographics, Negative Acts Questionnaire (NAQ), Beck Depression Inventory (BDI), and Rosenberg Self-Esteem (RSE) scale. A total of 426 samples were included for analysis, after discarding 72 samples due to grossly missing information. The response rate was $71.1 \%$.

Results Majority of the respondents were of the age group 25 to 29 years old. Nurses comprised $45.5 \%$ of the study population, followed by doctors $(37.8 \%)$, whilst the rest were medical assistants and midwives. Based on the definition of bullying as at least two occurrences of any negative act either on a weekly or daily basis, $20.7 \%$ of respondents had been bullied. $22.5 \%$ of the study group had mild to severe depression, and $8.5 \%$ had a low self-esteem. There was an association between depression and being bullied, with a $p$ value of $<0.001$. Those healthcare workers who had a low selfesteem were associated with higher exposure to bullying, with 